\section{The relationship between self efficacy, general self disease management strategies in coping with pain and quality of life in migraine patients: Testing a theoretical method}

\section{Migrenli hastalarda öz yeterlik, ağriyla başa ç1kmada kendi genel yönetim stratejileri ve yaşam kalitesi arasındaki ilişkinin incelenmesi: Teorik bir modelin test edilmesi}

\author{
İlknur Özkan ${ }^{1}$ \\ Nermin Olgun ${ }^{2}$
}

Özet

$\mathrm{Bu}$ araştırma, öz yeterliğin migrenli hastaların yaşam kalitesini doğrudan ve kendi kendine hastalık yönetimi becerileri aracillğı yoluyla ne kadar etkilediğini incelemek amaciyla, sosyal bilişsel teoriden temel alarak ve literatüre dayalı ilişkiler bağlamında nedensellik temelli bir modeli test etmek amaciyla planlanmıştır. Araştırmanın örneklemini bir nöroloji polikliniğinden seçilen 343 migren hastas1 oluşturmuştur. Veriler, görüşme formu, araştırmac1 tarafindan geliştirilen Migrenli Hastalarda Kendi Kendine Hastalık Yönetim Stratejileri Ölçeği, Migrenli Hastalarda Yaşam Kalitesi Ölçeği ve Standford Hasta Eğitim Araştırma Merkezi tarafindan geliştirilen Kronik Hastalıkları Yönetimde Öz Yeterlik Ölçeği (SelfEfficacy for Managing Chronic Disease 6-Item Scale, SEMCD) kullanılarak öz bildirim yöntemi ile toplanmıştır. Ölçeklerin yap1 geçerliliğini test etmek için açıklayıcı faktör analizi ve varimaks' eksen döndürme temel bileşenler analizi uygulanmıştır. Ölçeklerde yer alan maddelerin tamamı ve ölçeğin her bir alt boyutu için, iç tutarlık analizi yapılarak, Cronbach Alfa değerleri hesaplanmıştır. Araştırmada ileri sürülen model,

\footnotetext{
1 Yrd. Doç. Dr., Akdeniz Üniversitesi, Kumluca Sağlık Bilimleri Fakültesi, Hemşirelik Bölümü, ilknurozkan@akdeniz.edu.tr

2 Prof. Dr., Hasan Kalyoncu Üniversitesi, Sağlık Bilimleri Yüksekokulu, Hemşirelik Bölümü, nerminolgun@gmail.com
} 
Özkan, İ., \& Olgun, N. (2017). Migrenli hastalarda özyeterlik, ağrılla başa çıkmada kendi genel yönetin stratejileri ve yaşam kalitesi arasındaki ilişkinin incelenmesi: Teorik bir modelin test edilmesi. Journal of Human Sciences, 14(4), 3389-3404. doi:10.14687/jhs.v14i4.4787

analysis with latent variables in lisrel program. In SEM application, direct effect of selfefficacy on quality of life and indirect effect on self-disease management strategies were found to be statistically significant. Based on these results, self-efficacy can be thought to be a determinant of self-efficacy, quality of life of the patient and the patient's skills of using selfdisease management strategies. In order to improve the quality of life of migraine patients, their self-efficacy on disease management should be assessed and nursing practices should be planned to increase their confidence in the ability of preventing and managing migraine attacks.

$\begin{array}{llr}\text { Keywords: } & \text { Migraine; } & \text { Self-Disease } \\ \text { Management } & \text { Strategies; } & \text { Self-Efficacy; }\end{array}$ Structural Equity Model (SEM); Quality Of Life.

(Extended English abstract is at the end of this document) lisrel programında Yapısal Eșitlik Modeli (YEM)-örtük değişkenlerle yol analizi yapılarak test edilmiştir. YEM uygulamasında öz yeterliğin yaşam kalitesi üzerine doğrudan etkisi ve kendi kendine hastalık yönetim stratejileri üzerinden dolaylı etkisi istatiksel olarak anlamlı bulunmuştur. $\mathrm{Bu}$ sonuçlara dayanarak; öz yeterlik, hastanın yaşam kalitesini, kendi kendine hastalı yönetim stratejilerini kullanma becerisinin bir belirleyicisi olarak düşünülebilir. Migrenli hastaların yaşam kalitesini artırmak için migrenli hastaların hastalı yönetimi konusundaki öz yeterlikleri değerlendirilmeli, hemșirelik uygulamaları hastaların migren atağını önleme ve yönetme becerileri konusundaki kendilerine olan güvenini artıracak şekilde planlanmalıdir.

Anahtar Kelimeler: Migren; Kendi Kendine Hastalık Yönetim Stratejileri; Öz Yeterlik; Yapısal Eşitlik Modeli; Yaşam Kalitesi.

\section{Giriş}

Migren, bulantı-kusma, 1şığa ve sese hassasiyet gibi semptomların eşlik ettiği, genellikle tek taraflı yerleşim gösteren, zonklayıcı özellikte, epizodik baş ağrısıyla karakterize kronik nörolojik bir hastalıktır (Headache Classification Committee of the International Headache Society, 2013). Dünya genelinde görülme oranı, çalışmalarda değişiklik göstermekle birlikte, kadınlarda \%17.6, erkelerde \%8, genel nüfusta yaklaş1k \%14.7’dir (Stovner \& Andree, 2010; Smitherman, Burch, Sheikh \& Loder, 2013). Türkiye'de ise yapılan toplum tabanlı geniş epidemiyolojik bir araştırmada migren prevalansı \%16,4 (kadınlarda \%24,6, erkeklerde \%8,5) olarak bildirilmiştir (Ertaş et al., 2012).

Migrenin yaşamın en verimli yılları olan 20-55’li yaşları arasında sık görülmesi, yaşam kalitesine olumsuz etkileri yanında, toplumun üzerinde önemli ekonomik etkileri olan bir hastalıktır. Migren, hem atak sırasında hem de ataklar arasında iş yaşantısına, okul yaşantısına, aile ilişkilerine, arkadaş ilişkilerine, günlük aktivitelerin yerine getirilmesinde önemli derecede negatif etkiye sahiptir (Brna, Gordon \& Dooley, 2006; Duru, Auray \& Gaudin, 2004; Landy, Runken, Bell, Higbie \& Haskins, 2011; Vladetic, Janculjak, Soldo, Krali, \& Buljan, 2017; Mennini, Gitto \& Martelletti, 2008). Migren, yapılan araştırmalarda en çok kısıtlılık yapan kronik hastalıklar arasında yedinci sırada ele alınmıştır (Steiner, Stovner, \& Gretchen, 2013; Vladetic, Janculjak, Soldo, Krali, \& Buljan, 2017).

Öz yeterlik, kişinin spesifik bir davranışı yerine getirmede kişisel inancı olarak tanımlanmaktadır. Öz yeterlilik ilk defa Bandura tarafından sosyal bilişsel teoride ele alınmıştır. Öz-yeterlik, davranış üzerine etkili olduğu düşünülen sosyal bilişsel teorinin temel bileşenlerinden birisidir (Bandura, 1977). Sosyal bilişsel teoriye göre, hastaların sağlık davranışlarını yerine getirme konusundaki kendilerine duydukları güven sağlık sonuçlarını etkilemektedir (Bandura, 2004; Marks, Allegrante \& Lorig, 2005). 
Özkan, İ., \& Olgun, N. (2017). Migrenli hastalarda özyeterlik, ağrılla başa çıkmada kendi genel yönetin stratejileri ve yaşam kalitesi arasındaki ilişkinin incelenmesi: Teorik bir modelin test edilmesi. Journal of Human Sciences, 14(4), 3389-3404. doi:10.14687/jhs.v14i4.4787

Baş ağrısına spesifik öz yeterlik, baş ağrısı epizotlarını önlemek ya da baş ağrısıyla ilişkili yetersizliği yönetmek amacıyla yapılan aktiviteleri yerine getirmedeki güveni gösterir. Migren yönetiminde hastanın hastalığa adaptasyonu çok önemlidir. Öz yeterlik hastalığa adaptasyonda anahtar rol oynamaktadır. Baş ağrısını yönetmede ve önlemede uygulanacak girişimler konusunda algılanan bireysel farklılıklar, baş ağrısı problemlerine bireysel adaptasyonu ile ilişkilidir (Willis, 2016; French, et al., 2002; Seng \& Holroyd, 2010; Zacharoff \& Chiauzzi, 2012; Kleiboer, et al. 2014; Bromberg, et al.,2014). Migren ve diğer kronik hastalığ1 olan bireylerde yapilan araştırmalarda, öz yeterlik arttıkça yasam kalitesi ve hastalık yönetim davranışlarının arttığ1, ağrı yoğunluğu, anksiyete ve deprsesif semptomların azaldığ1 görülmüştür ( French, et al., 2000; Seng \& Holroyd, 2010; Zacharoff \& Chiauzzi, 2012; Kleiboer, et al., 2014; Bromberg, et al., 2014; Haugland, Wahl, Hofoss \& DeVon 2016; Wilski \& Tasiemski, 2016; Yeung \& Lu, 2014; Hunt, et al.,2012).

Migrenli hastaların kendi kendine hastalık yönetim davranışları konusundaki öz yeterliklerini değerlendirmek oldukça önemlidir. Sağlık profesyonelleri, düşük öz yeterliğe sahip hastaları belirleyerek, hastalıkla başa çıkma becerileri konusunda öz yeterliklerini artıracak müdahalelerde bulunabilirler, hastaların kendi kendine hastalık yönetim becerilerini ve yaşam kalitelerini olumlu yönde etkileyebilirler. Bu kapsamda araştırmanın amacı sosyal bilişsel teoriden yola çıkarak ve yapılan bazı araştırmalara dayanarak migrenli hastalarda öz yeterlilik, hastaların ağrıyla başa çıkmada kullandıkları kendi genel yönetim stratejileri ve yaşam kalitesi arasındaki ilişkiyi öngören bir model oluşturmak ve bu modeli test etmektir.

\section{Yöntem}

\subsection{Araştırmanın Tasarımı, Örneklemi ve Yeri}

Araştırma metodolojik ve tanımlayıcı olarak tasarlanmıştır. Araştırmanın evrenini Haziran 2011Haziran 2012 tarihleri arasında bir üniversite hastanesinin Nöroloji Polikliniğinde Uluslararası Baş Ağrıs1 Derneği'nin (IHS) kriterlerine göre (Headache Classification Committee of the International Headache Society, 1988). migren tanısı almış ayaktan izlenen hastalar oluşturmuştur. Örneklem büyüklüğü, Türkiye' de migren prevalansı \% 16.4 oranında görüldüğü ile ilgili önceki araştırma sonuçları göz önüne alınarak hesaplanmıştır. Örneklem büyüklüğü, \% 95 olasıllk, d= 0.0052' lik sapma ve görülme sıklığ1 \% 16.4 olarak hesaplandığında 258 olarak hesaplanmıştır. Metodolojik araştırmalarda örneklem hacminin ölçek madde sayının 5-10 kat büyüklüğünde olması gerektiği göz önünde bulundurularak, araştırmanın örneklemini basit rastgele örnekleme yöntemi ile en az 6 ay önce IHS kriterlerine göre migren tanısı alan, MIDAS puanı $>5$ olan, koruyucu tedavi kullanmayan, 18 yaşından büyük olan, araştırmaya katılmaya istekli olan, başka bir kronik hastalığı olmayan, Türkçe okuyup yazabilen 343 migren hastası oluşturmuştur.

\subsection{Araştırmanın Modeli}

$\mathrm{Bu}$ araştırma, öz yeterliğin migrenli hastaların yaşam kalitesini doğrudan ve kendi kendine hastalık yönetimi becerileri aracılığ1 yoluyla ne kadar etkilediğini incelemek amacıyla, sosyal bilişsel teoriden temel alarak ve literatüre dayalı ilişkiler bağlamında nedensellik temelli bir modeli test etmek amacıyla planlanmıştır. Literatürde yer alan araştırmalarda araştırmanın değişkenlerini oluşturan öz yeterlik, kendi kendine hastalık yönetimi ve yaşam kalitesi arasında ilişki bulunmuştur (French, et al., 2000; Seng \& Holroyd, 2010; Zacharoff \& Chiauzzi, 2012; Kleiboer, et al., 2014; Bromberg, et al., 2014; Haugland, Wahl, Hofoss \& DeVon 2016; Wilski \& Tasiemski, 2016; Yeung \& Lu, 2014; Hunt, et al., 2012) . Bu araştırma modelinde öz-yeterlik yordayıcı değissken yaşam kalitesi yordanan ve kendi kendine hastalık yönetim beceriler ise aracı değişken olarak ele alınmıştır. Bu modele göre: 1) Migrenli hastalarda öz yeterlik düzeyi, hastaların ağrıyla başa çıkmada kullandıkları kendi genel yönetim stratejilerini doğrudan etkiler. (2) Migrenli hastalarda öz yeterlik düzeyinin, hastaların yaşam kalitesini doğrudan etkiler. (3) Migrenli hastalarda öz 
Özkan, İ., \& Olgun, N. (2017). Migrenli hastalarda özyeterlik, ağrılla başa çıkmada kendi genel yönetin stratejileri ve yaşam kalitesi arasındaki ilişkinin incelenmesi: Teorik bir modelin test edilmesi. Journal of Human Sciences, 14(4), 3389-3404. doi:10.14687/jhs.v14i4.4787

yeterlik düzeyi, kendi kendine hastalık yönetimi becerileri aracılığı ile yaşam kalitesini dolaylı yoldan etkiler (Şekil 1).

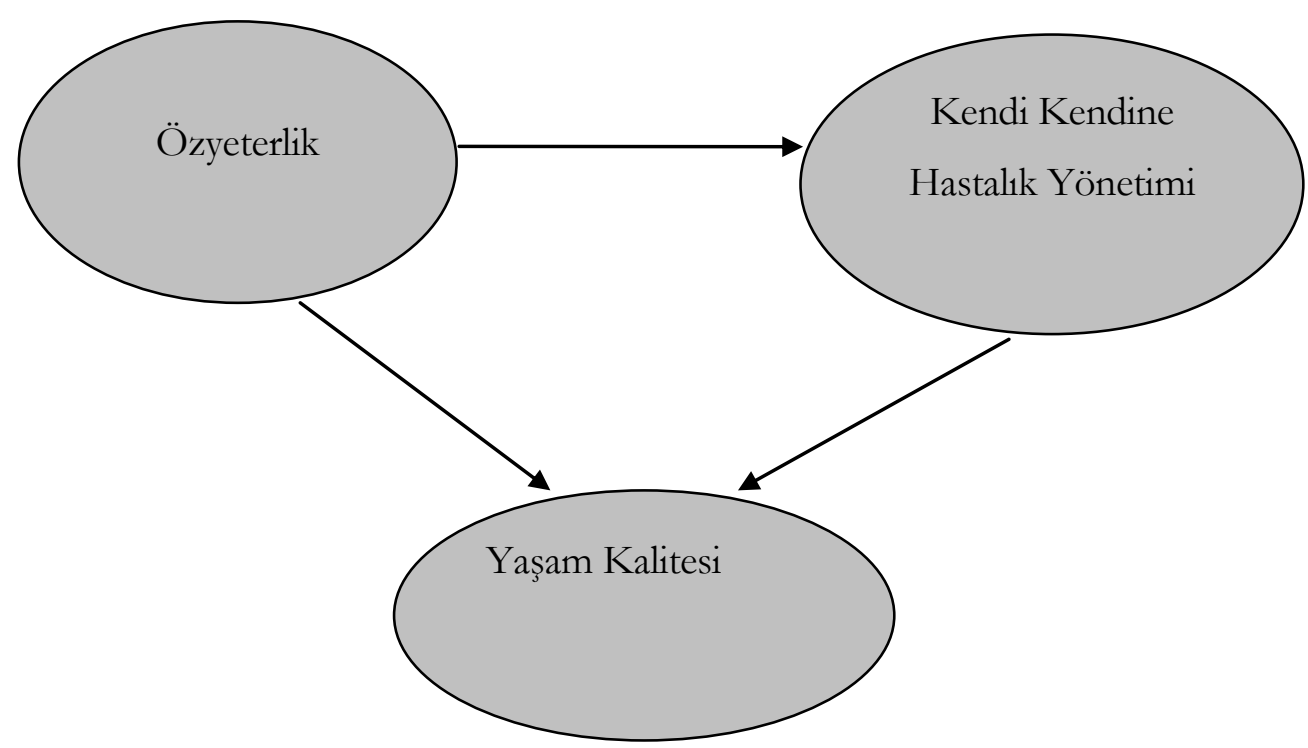

Şekil 1 Öz yeterlilik, Kendi Kendine Hastalık Yönetimi ve Yaşam Kalitesi Arasındaki İlişkiyi Öngören Araştırmanın Modeli

\subsection{Araştırma Verilerin Toplanması}

Araştırmaya, dahil edilme kriterlerine uyan hastalara araştırmacı tarafindan hazırlanan bilgi formu, Türkçeye uyarlanan Kronik Hastalıkları Yönetimde 6 Maddelik Öz Yeterlik Ölçeği( SelfEfficacy for Managing Chronic Disease 6-Item Scale, SEMCD), araştırmacı tarafindan geliştirilen Migrenli Hastalarda Kendi Kendine Hastalık Yönetim Stratejileri Ölçeği (MHKKHYSÖ), Migrenli Hastalarda Yaşam Kalitesi Ölçeği (MHYKÖ) uygulanmıştır.

Kronik Hastalıkları Yönetimde Öz Yeterlik Ölçeği (SEMCD): Standford Hasta Eğitim Araştırma Merkezi tarafindan geliştirilmiştir. Ölçek birçok kronik hastalıklarda karşılaşılan, ortak olan genel semptom kontrolü, rol fonksiyonu, emosyonel fonksiyonu, doktorla iletişim alanını kapsayan 6 maddeden ve tek boyuttan oluşmaktadır. Orijinal ölçeğin Cronbach Alfa güvenirlik katsayıs1 0.91'dir. Ölçeğin Türkçe uyarlaması araştırmacı tarafından yapılmıştır. SEMCD ölçeğinin dil geçerliği geri çeviri ve uzman paneli yöntemleri ile yapıldı. Ölçeğin yapı geçerliğinin değerlendirilmesinde açıklayıcı faktör analizi yöntemi uygulanmıştır. Kaiser- Meyer Olkin testi $(\mathrm{KMO}=0.909>0.60)$ uygulamasında örneklem büyüklügü faktör analizi uygulanması için yeterli bulunmuştur. Faktör analizi sonucunda değişkenlerin toplam açıklanan varyansı \% 83.17 olan bir faktör altında toplanmıştır. Ölçeğin güvenirliğini hesaplamak için iç tutarlılık katsayısı olan "Cronbach Alpha" hesaplanmıştır. Ölçeğin cronbach alfa güvenirlik katsayısı $=0.958$ olarak çok yüksek bulunmuştur.

Migrenli Hastalarda Kendi Kendine Hastalık Yönetim Stratejileri Ölçeği (MHKKHYSÖ): Migrene bağlı baş ağrısını yönetmede ve önlemede hastanın kendi kullandığı stratejileri değerlendirmek amacıyla araştırmacı tarafından geliştirilmiştir. 17 maddeden ve 4 alt boyuttan oluşan bir ölçektir. Ölçek maddelerinin kapsam geçerliliği Lawshe tekniğine göre değerlendirildi. Her bir madde uzman görüşleri "madde hedeflenen yapıyor ölçüyor", "madde yapı ile ilişkili ancak gereksiz" ya da "madde hedeflenen yapıyı ölçmez" şeklinde derecelendirilmiş ve nöroloji alanında 6 uzman kişinin görüşüne sunulmuştur. Tüm maddelerin Kapsam Geçerlik Oranının $(K G O)=1$ olduğu görülmüştür. Ölçeğin yap1 geçerliğini değerlendirmek için bu araştırmada 
Özkan, İ., \& Olgun, N. (2017). Migrenli hastalarda özyeterlik, ağrılla başa çıkmada kendi genel yönetin stratejileri ve yaşam kalitesi arasındaki ilişkinin incelenmesi: Teorik bir modelin test edilmesi. Journal of Human Sciences, 14(4), 3389-3404. doi:10.14687/ihs.v14i4.4787

açıklayıcı faktör analizi yöntemi uygulanmıştır. KMO testi $(\mathrm{KMO}=0.878>0.60)$ uygulamasında örneklem büyüklüğü faktör analizi uygulanmasi için yeterli olduğu bulunmuştur. Faktör analizi sonucunda değişkenler toplam açıklanan varyansı \%63.283 olan 4 faktör altında toplanmıştır. Birinci faktörde yer alan maddeler palyatif stratejiler, ikinci faktörde yer alan maddeler kaçınılması gereken stratejiler, üçüncü faktörde yer alan maddeler sistematik bilişsel ve davranışsal stratejiler, dördüncü faktörde yer alan maddeler sistematik kas gerilimini azaltan stratejiler olarak adlandırılmıştır. MHKKHYSÖ'nin alt boyutlarının açıklanan varyans değerleri palyatif stratejiler alt boyutunun \%19.338, kaçınılması gereken stratejiler alt boyutunun \%14.993, sistematik bilişsel ve davranışsal stratejiler alt boyutunun \%14.71, sistematik kas gerilimini azaltan stratejiler alt boyutunun \%14.242 olarak saptanmıştır. MHKKHYSÖ'nin cronbach alfa güvenirlik katsayıs1, ölçeğin tamamı için 0,95 olarak bulunmuştur.

Migrenli Hastalarda Yaşam Kalitesi Ölçeği (MHYKÖ): Migrenin hastaların yaşam kalitelerini nasıl etkilediğini değerlendirmek amacıyla araştırmacı tarafından geliştirilmiştir. 5'li Likert tipi, toplam 23 maddeden ve dört alt boyuttan oluşan bir ölçektir. Ölçek maddelerinin kapsam geçerliliği Lawshe tekniğine göre değerlendirildi. Her bir madde uzman görüşleri "madde hedeflenen yapıyor ölçüyor", "madde yapı ile ilişkili ancak gereksiz" ya da "madde hedeflenen yapıyı ölçmez" şeklinde derecelendirilmiş ve nöroloji alanında 6 uzman kişinin görüşüne sunulmuştur. Tüm maddelerin Kapsam Geçerlik Oranının (KGO)= 1 olduğu görülmüştür. Ölçeğin yap1 geçerliliğini değerlendirmek için bu araştırmada açıklayıc1 faktör analizi uygulanmıştır. KMO testi uygulamasında $(\mathrm{KMO}=0.951>0.60)$ örneklem büyüklügünün faktör analizi uygulanması için yeterli bulunmuştur. Faktör analizi sonucunda değişkenler toplam açıklanan varyansı \% 72.374 olan 4 faktör altında toplanmıştır. Birinci faktörde yer alan maddeler sosyal fonksiyonlarda kayıp, ikinci faktörde yer alan maddeler emosyonel alan, üçüncü faktörde yer alan maddeler sosyal ilişkilerde kısıtlama, dördüncü faktörde yer alan maddeler semptomatik alan olarak adlandırılmıştır. Alt boyutlarının açıklanan varyans değerleri; sosyal fonksiyonlarda kayıp \%21.852, emosyonel alan alt boyutunun \%18.754, sosyal ilişkilerde kısıtlama alt boyutunun \%16.756, semptomatik alan alt boyutunun \%15.012 olarak saptanmıştır. MHYKÖ'nin tamamı için cronbach alfa güvenirlik katsayısı 0,95 olarak bulunmuştur. Tablo 1'de geliştirilen iki ölçeğe ilişkin faktörlere ait elde edilen cronbach alpha güvenirlik katsayıları sunulmuştur.

Tablo 1 Ölçeklerin Güvenilirlik Katsayıları

\begin{tabular}{lc}
$\begin{array}{l}\text { Migrenli Hastalarda Kendi Kendine Hastalık Yönetim Stratejileri } \\
\text { Ölçeği }\end{array}$ & $\begin{array}{l}\text { Cronbach's } \\
\text { Alpha }\end{array}$ \\
\hline 1- Palyatif stratejiler & $\mathbf{0 . 8 5 9}$ \\
2- Kaçınılması gereken stratejiler & $\mathbf{0 . 7 5 6}$ \\
3- Sistematik bilişsel ve davranışsal stratejiler & $\mathbf{0 . 8 1 6}$ \\
4- Sistematik kas gerilimini azaltan stratejiler & $\mathbf{0 . 8 4 2}$
\end{tabular}

\section{Migrenli Hastalarda Yaşam Kalitesi Ölçeği}

1- Sosyal fonksiyonlarda kayip

2- Emosyonel alan

3- Sosyal ilişkilerde kısıtlama

4- Semptomatik alan

Kronik Hastalıkları Yönetimde Öz Yeterlik Ölçeği

Öz yeterlik 
Özkan, İ., \& Olgun, N. (2017). Migrenli hastalarda özyeterlik, ağrılla başa çıkmada kendi genel yönetin stratejileri ve yaşam kalitesi arasındaki ilişkinin incelenmesi: Teorik bir modelin test edilmesi. Journal of Human Sciences, 14(4), 3389-3404. doi:10.14687/ihs.v14i4.4787

\section{4.Verilerin İstatiksel Analizi}

Araştırmada elde edilen bulgular değerlendirilirken, istatistiksel analizler için SPSS (Statistical Package for Social Sciences) for windows 17.0 programı, açıklayıcı faktör analizi, doğrulayıcı faktör analizi ve yapısal eşitlik modeli için lisrel 8.51 programı kullanılmıştır.

Örneklem büyüklügünün faktör analizi için uygunluğunu değerlendirmede Kaiser-MeyerOlkin (KMO) testi ve Bartlett's Sphericity testi uygulanmıştır. Ölçeğin yapı geçerliliğini değerlendirmek için, açıklayıcı faktör analizi ve varimaks’ eksen döndürme temel bileşenler analizi uygulanmıştır. Ölçeklerin güvenirliğini değerlendirmek için araştırmada madde analizleri ve cronbach alfa katsayıları kullanılmıştır.

Öz yeterlilik, kendi kendine hastalık yönetim stratejileri, yaşam kalitesi arasındaki ilişkiyi açıklamak/ tahmin etmek üzere geliştirilen model, lisrel programında Yapısal Eşitlik Modeli (YEM)-örtük değişkenlerle yol analizi yapılarak test edilmiştir. $\mathrm{Bu}$ analizde $\mathrm{t}$ değerleri için anlamlılık düzeyleri 0.05 düzeyine karşılık gelen 1.96 değeri seçilmiştir.

\subsection{Araştırmanın Etik Yönü}

Araştırmanın etik ilkelere uygunluğu Marmara Üniversitesi Tip Fakültesi girişimsel olmayan etik kurul tarafindan değerlendirildi ve etik onam (MAR-YÇ-2009-0152/08.05.2009) alınmıştır. Uygulama sırasında hastalara araştırmacı tarafindan gerekli açıklamalar yapıldıktan sonra yazılı onamları alınmıştır. Standford Patient Education Research Center tarafindan SEMCD ölçeğinin izinsiz kullanımına izin verilmiştir.

\section{BULGULAR}

3.1.Teorik modelin oluşturulması: Migrenli hastalarda öz yeterlik, kendi kendine hastalık yönetimi ve yaşam kalitesi ilişkilerini gösteren bir yapısal eşitlik modeli oluşturulmuştur. Bu teorik model beş bölümden oluşmaktadır: Ölçüm bileşenleri: (i) çalışmanın dışsal değişkeni olan öz yeterlik (ii)çalışmanın aracı değişkeni olan kendi kendine hastalık yönetim stratejilerinin dört gözlenen değişkeni [palyatif stratejiler, kaçınılması gereken stratejiler, sistematik bilişsel ve davranışsal stratejiler, sistematik kas gerilimini azaltan stratejiler]; (iii) çalışmanın içsel değişkeni yaşam kalitesinin dört gözlenen değişkeni [sosyal fonksiyonlarda kayıp, emosyonel alan, sosyal ilişkilerde kısıtlama, semptomatik alan] tarafından oluşmaktadır. Yapısal eşitlik bileşenleri ise teorik olarak, örtük değişkenler arasındaki ilişkileri formüle etmektedir: (1v) Öz yeterliğin yaşam kalitesine direk etkileri olduğu ve (v) öz yeterliğin yaşam kalitesine kendi kendine hastalık yönetimi becerileri aracıllğ̆1 ile etkileri olduğu varsayılmıştır. Modelde, gözlenen değişkenler dikdörtgen; örtük değişkenler ise oval kutucuklarla, örtük değişkenlerin gözlenen değişkenler üzerindeki yordayıcı etkisi doğrusal tek yönlü çizgiler ile gösterilmiştir. Her gözlenen değisskenin, hata terimi de bulunmaktadır. (Şekil 2 ve 3 ).

3.2.Teorik modelin test edilmesi: Lisrel programı kullanılarak yapısal eşitlik modeli oluşturulunca, öncelikle modifikasyon indisleri incelenmiştir. Yapısal eşitlik modeli testi için modifikasyon indisleri kullanılarak doymuş model elde edilmiştir. Yon22 - yon11, yon20 - yon2, yon13 - yon14, yon05 - yon23, myko14 - myko1, myko14 - myko15, myko16 - myko19, myko29 myko30, myko05 - myko08, ozyet5 - ozyet6 maddelerinin hataları model yapısı içinde korele edilmiştir (Şekil 2). Bu soru eşleşmelerinin teorik olarak birbirine yakın sorular olduğu görülmüştür.

Modelin uyum iyiliği istatistikleri incelendiğinde; RMSEA değeri 0.075 olarak bulunmuştur. Ki kare değeri 2811.11; p=0.000 istatistiksel olarak anlamlı bulunmuştur. İlgili p değerinin anlamlı olmaması istenen bir durumdur. Ancak çoğu durumda, doğrulayıcı faktör analizinde örneklemin büyük olması nedeniyle $\mathrm{p}$ değerinin anlamlı olma durumu beklenen bir durumdur. Ki- karenin serbestlik derecesine bölünmesiyle $\left(\chi^{2} / \mathrm{sd}=2811.11 / 955=2.94\right)$ elde edilen değer ki- kare değerine göre daha güvenilir bir değerdir. Elde ettiğimiz değer 3’ ten küçük olması nedeniyle modelin kabul edilebilir sınırlar içinde yer aldığ1 görülmüştür. Diğer uyum 
Özkan, İ., \& Olgun, N. (2017). Migrenli hastalarda özyeterlik, ağrılla başa çıkmada kendi genel yönetin stratejileri ve yaşam kalitesi arasındaki ilişkinin incelenmesi: Teorik bir modelin test edilmesi. Journal of Human Sciences, 14(4), 3389-3404. doi:10.14687/ihs.v14i4.4787

kriterlerinden SRMR yapısal eşitlik modelinin kabul edilebilir uyum sınırları içinde olduğu görülmüştür. Yapısal eşitlik modeline ilişkin uyum kriterleri Tablo 2'de sunulmuştur.

Tablo 2 Yapısal Eşitlik Modeline İlişkin Uyum Kriterleri

\begin{tabular}{|c|c|c|c|c|}
\hline $\begin{array}{l}\text { Uyum } \\
\text { Kriteri }\end{array}$ & İyi Uyum & $\begin{array}{l}\text { Kabul Edilebilir } \\
\text { Sinir }\end{array}$ & $\begin{array}{l}\text { Uyum İyiliği } \\
\text { sonuçları }\end{array}$ & Sonuç \\
\hline Ki-kare & $0<$ Ki-kare $<2$ sd & 2 sd $<$ Ki-kare $<3$ sd & $\begin{array}{l}\text { Ki-kare }=2811.11< \\
3 \text { sd }=2865\end{array}$ & $\begin{array}{l}\text { Kabul } \\
\text { edilebilir } \\
\text { uyum }\end{array}$ \\
\hline p değeri & $0.05<\mathrm{p}<1.00$ & $0.01<\mathrm{p}<0.05$ & 0.000 & \\
\hline $\begin{array}{l}\text { Ki- } \\
\text { kare/sd }\end{array}$ & $0<\mathrm{Ki}$-kare $/ \mathrm{sd}<2$ & $2<\mathrm{Ki}$-kare $/ \mathrm{sd}<3$ & $\begin{array}{l}\text { Ki-kare } / \text { sd }=2.94< \\
3\end{array}$ & $\begin{array}{l}\text { Kabul } \\
\text { edilebilir } \\
\text { uyum }\end{array}$ \\
\hline RMSEA & $0<$ RMSEA $<0.5$ & $0.05<$ RMSEA $<0.08$ & 0,075 & $\begin{array}{l}\text { Kabul } \\
\text { edilebilir } \\
\text { uyum }\end{array}$ \\
\hline p değeri & $0.10<\mathrm{p}<1.00$ & $0.05<\mathrm{p}<1.00$ & 0.000 & \\
\hline SRMR & $0<\mathrm{SRMR}<0.05$ & $0.05<$ SRMR $<0.10$ & 0.072 & $\begin{array}{l}\text { Kabul } \\
\text { edilebilir } \\
\text { uyum }\end{array}$ \\
\hline CFI & $0.97<\mathrm{CFI}<1.00$ & $0.95<$ CFI $<0.97$ & 0.86 & $\begin{array}{l}\text { Kötü } \\
\text { uyum }\end{array}$ \\
\hline GFI & $0.95<\mathrm{GFI}<1.00$ & $0.90<\mathrm{GFI}<0.95$ & 0.74 & $\begin{array}{l}\text { Kötü } \\
\text { uyum }\end{array}$ \\
\hline AGFI & $0.95<\mathrm{AGFI}<1.00$ & $0.90<$ AGFI $<0.95$ & 0.70 & $\begin{array}{l}\text { Kötü } \\
\text { uyum }\end{array}$ \\
\hline
\end{tabular}

RMSEA: Root Mean Square Error of Approximation, SRMR:Standardized Root Mean Square Residual, CFI: Comparative Fit Index,, GFI: Goodness of Fit Index , AGFI: Adjusted Goodness of Fit Index

Oluşturduğumuz model kabul edilebilen uyum değerleri arasında yer almasıyla, yol analiziyle yapısal modelin test edilmesi aşamasına geçilmiştir. Anlamlı ilişkilerin belirlenebilmesi amacıyla t-değerleri (\%5 anlamlılık düzeyinde, kritik değer 1.96) incelenmiştir. Yapısal eşitlik modeli analizine göre; öz yeterlik düzeyinin, migrenli hastaların kendi kendine hastalık yönetim stratejileri ölçeği palyatif stratejiler alt boyutuna $(t=8.70 ; \mathrm{p}<0.05)$, kaçınılması gereken stratejiler alt boyutuna $(\mathrm{t}=7.72 ; \mathrm{p}<0.05)$, sistematik bilişsel ve davranışsal stratejiler alt boyutuna $(\mathrm{t}=10.10$; $\mathrm{p}<0.05)$, sistematik kas gerilimini azaltan stratejiler $(\mathrm{t}=10.71 ; \mathrm{p}<0.05)$ alt boyutuna doğrudan etkisi istatistiksel olarak anlamlı bulunmuştur (Şekil 2). Öz yeterlik düzeyinin bir birim arttığında, palyatif stratejilerin 0.87 birim, kaçınılması gereken stratejilerin 0.68 birim, sistematik bilişsel ve davranışsal stratejilerin 0.95 birim, sistematik kas gerilimini azaltan stratejilerin 0.80 birim arttığ1 belirlenmiştir (Tablo 3).

Öz yeterlik düzeyinin, yaşam kalitesi ölçeği sosyal fonksiyonlarda kayıp alt boyutuna ( $\mathrm{t}=$ 9.63; $\mathrm{p}<0.05)$, emosyonel alan alt boyutuna $(\mathrm{t}=-11.88 ; \mathrm{p}<0.05)$, sosyal ilişkilerde kısıtlama alt boyutuna $(\mathrm{t}=-11.03 ; \mathrm{p}<0.05)$, semptomatik alan alt boyutuna $(\mathrm{t}=-10.41 ; \mathrm{p}<0.05)$ doğrudan etkisi istatistiksel olarak anlamlı bulunmuştur (şekil 2). Öz yeterlik düzeyinin bir birim arttığında, sosyal fonksiyonlarda kayıbın 0.62 birim, emosyonel alanın 0.66 birim, sosyal ilişkilerde kısıtlamanın 0.65 birim, semptomatik alanın 0.64 birim azaldığı belirlenmiştir (Tablo 3). 
Özkan, İ., \& Olgun, N. (2017). Migrenli hastalarda özyeterlik, ağrılla başa çıkmada kendi genel yönetin stratejileri ve yaşam kalitesi arasındaki ilişkinin incelenmesi: Teorik bir modelin test edilmesi. Journal of Human Sciences, 14(4), 3389-3404. doi:10.14687/jhs.v14i4.4787

Öz yeterlik düzeyinin, yaşam kalitesi ölçeği sosyal fonksiyonlarda kayıp alt boyutuna ( $\mathrm{t}=$ 4.12; $\mathrm{p}<0.05)$, emosyonel alan alt boyutuna $(\mathrm{t}=-4.51 ; \mathrm{p}<0.05)$, sosyal ilişkilerde kısıtlama alt boyutuna $(\mathrm{t}=-4.35 ; \mathrm{p}<0.05)$, semptomatik alan alt boyutuna $(\mathrm{t}=-4.57 ; \mathrm{p}<0.05)$ migrenli hastalarin kendi kendine hastalık yönetim stratejileri ölçeği üzerinden dolaylı etkisi istatistiksel olarak anlamlı bulunmuştur (Şekil 2). Öz yeterlik düzeyinin bir birim arttığında, sosyal fonksiyonlarda kaybın dolaylı olarak 2.37 birim, emosyonel alanın dolaylı olarak 1.88 birim, sosyal ilişkilerde kısıtlamanın dolaylı olarak 2.38 birim, semptomatik alanın dolaylı olarak 2.62 birim azaldığ1 belirlenmiştir (Tablo 3).

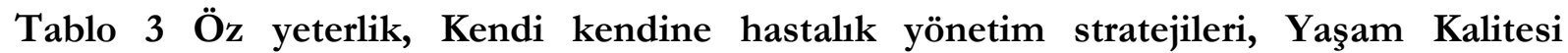
Arasındaki Toplam Etki Katsayıları ve Belirlilik Katsayısı Matrisi

\begin{tabular}{|c|c|c|c|c|}
\hline $\begin{array}{lll}\text { Kendi } & \text { Kendine } & \text { Hastalık } \\
\text { Yönetimi } & & \\
\end{array}$ & \multicolumn{2}{|c|}{ Öz yeterlik } & \multicolumn{2}{|c|}{$\begin{array}{l}\text { Kendi Kendine Hastalık } \\
\text { Yönetimi }\end{array}$} \\
\hline & Yol Katsayıs1 & $\mathrm{R}^{2}$ & Yol Katsayıs1 & $\mathrm{R}^{2}$ \\
\hline 1-Palyatif Sratejiler & 0.87 & 0,76 & & \\
\hline 2-Kaçınılmas1 Gereken Stratejiler & 0.68 & 0.46 & & \\
\hline $\begin{array}{l}\text { 3-SistematikBilişşsel } \quad \text { Davranışsal } \\
\text { Stratejiler }\end{array}$ & 0,95 & 0.90 & & \\
\hline $\begin{array}{l}\text { 4-Sistematik Kas } \quad \text { Gerilimini } \\
\text { Azaltan Stratejiler }\end{array}$ & 0.80 & 0.63 & & \\
\hline \multicolumn{5}{|l|}{ Yaşam Kalitesi } \\
\hline 1-Sosyal Fonksiyonlarda Kayıp & $-0,62$ & 0.39 & -2.37 & 0.90 \\
\hline 2-Emosyonel Alan & $-0,66$ & 0.44 & -1.88 & 0,68 \\
\hline 3-Sosyal İlişkilerde Kısıtlama & -0.65 & 0.42 & -2.38 & 0,88 \\
\hline 4-Semptomatik Alan & $-0,64$ & 0.41 & -2.62 & 0,93 \\
\hline
\end{tabular}

$\mathrm{R}^{2}$ : Belirlilik Katsayıs1 

yaşam kalitesi arasındaki ilişkinin incelenmesi: Teorik bir modelin test edilmesi. Journal of Human Sciences, 14(4), 3389-3404. doi:10.14687/ihs.v14i4.4787

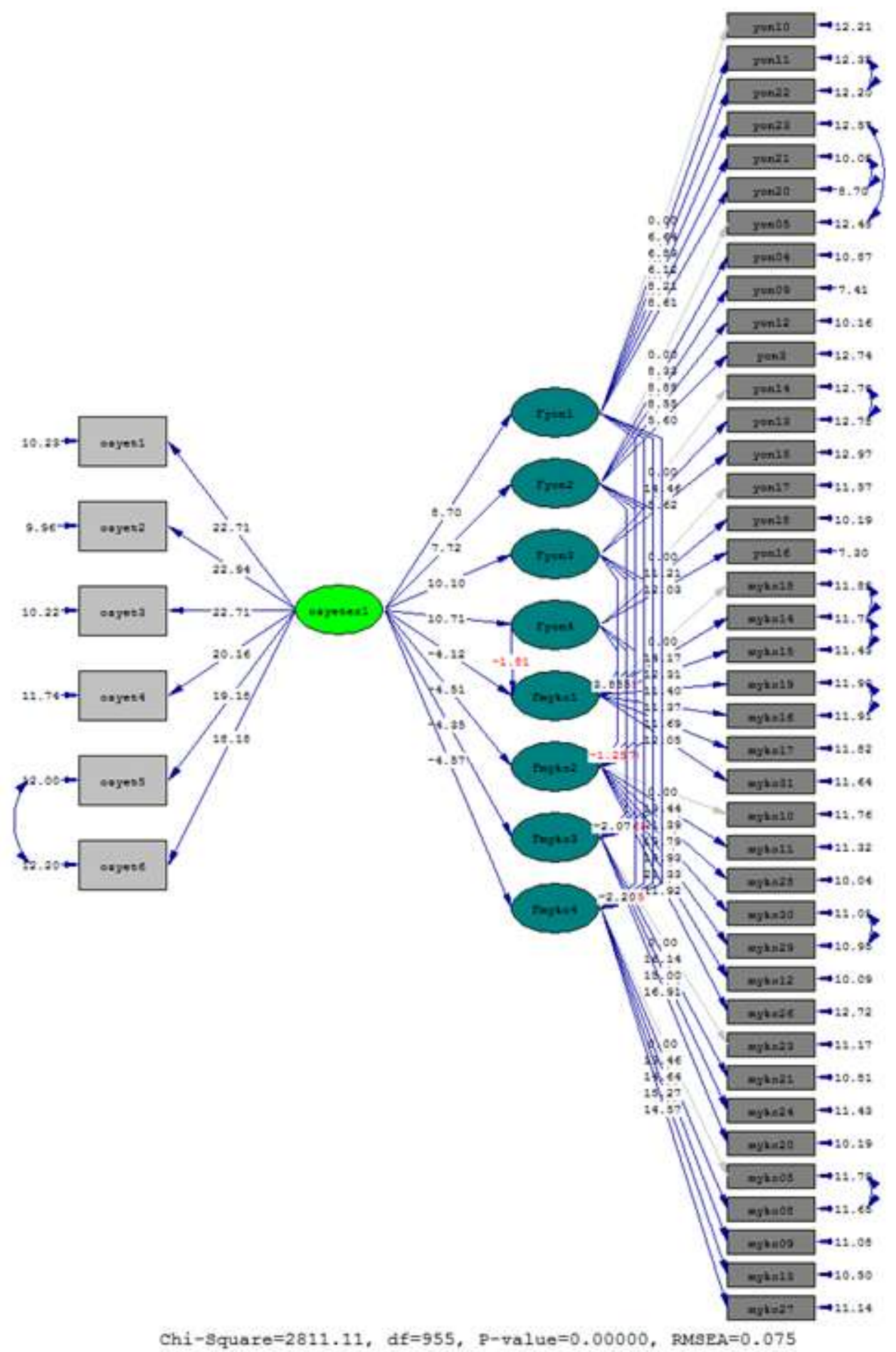

Şekil 2. Yapısal Eşitlik Modeli t Testi Sonuçları (yon= kendi kendine yönetim stratejileri ölçeği, mykö= migrenli hastalarda yaşam kalitesi ölçeği, ozyeter1=öz yeterlik) 

yaşam kalitesi arasındaki ilişkinin incelenmesi: Teorik bir modelin test edilmesi. Journal of Human Sciences, 14(4), 3389-3404. doi:10.14687/ihs.v14i4.4787

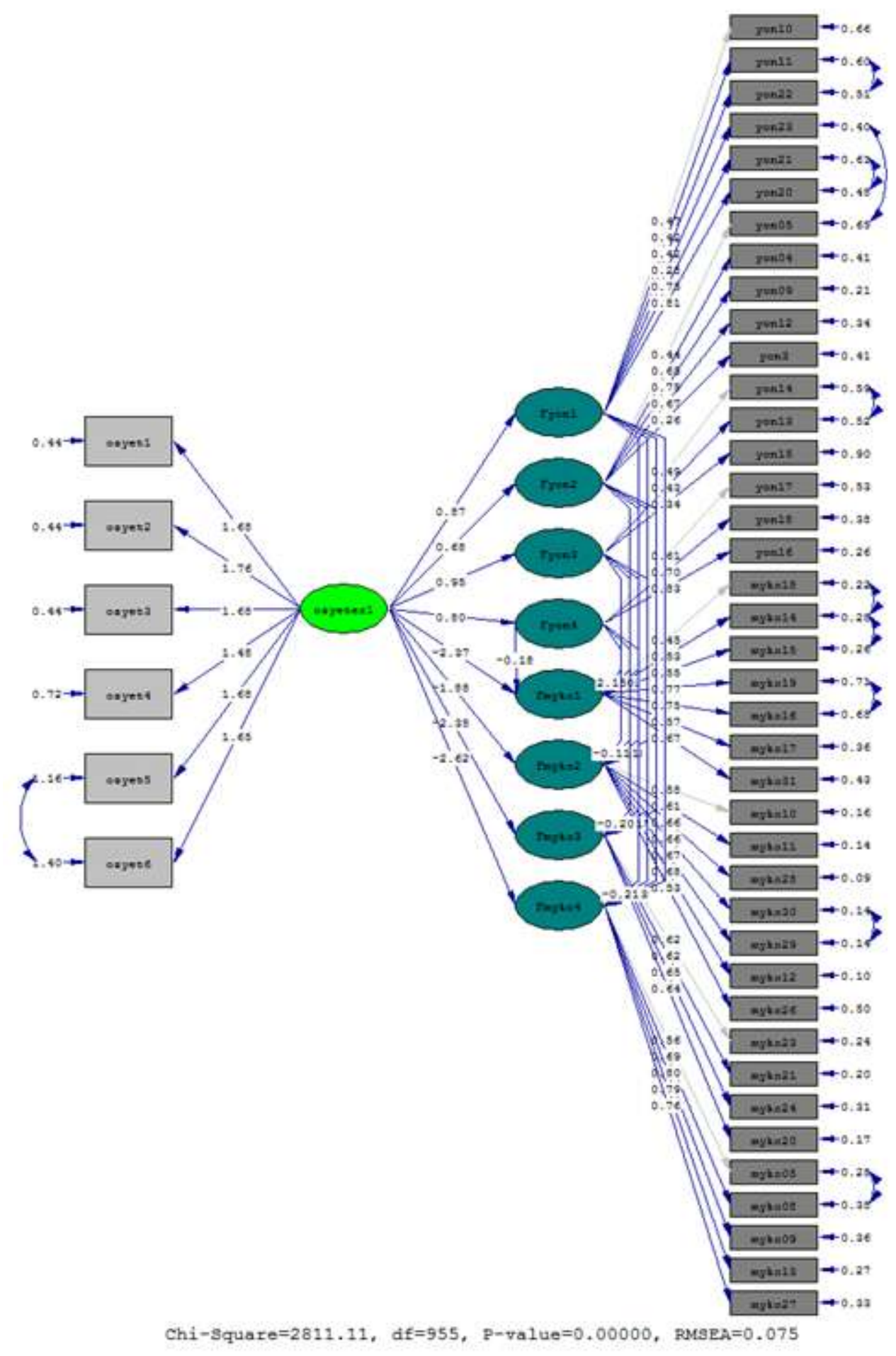

Şekil 3. Yapısal Eşitlik Modeli Kestirim Sonuçları (yon= kendi kendine yönetim stratejileri ölçeği, mykö= migrenli hastalarda yaşam kalitesi ölçeği, ozyeter1= öz yeterlik) 
Özkan, İ., \& Olgun, N. (2017). Migrenli hastalarda özyeterlik, ağrılla başa çıkmada kendi genel yönetin stratejileri ve yaşam kalitesi arasındaki ilişkinin incelenmesi: Teorik bir modelin test edilmesi. Journal of Human Sciences, 14(4), 3389-3404. doi:10.14687/ihs.v14i4.4787

\section{Tartışma}

$\mathrm{Bu}$ araştırma, öz yeterliğin migrenli hastaların yaşam kalitesini doğrudan ve kendi kendine hastalık yönetimi becerileri aracılı̆̆ yoluyla ne kadar etkilediğini incelemek amacıyla, sosyal bilişsel teoriden temel alarak ve literatüre dayalı ilişkiler bağlamında nedensellik temelli bir modeli test etmek amacıyla yapılmıştır. İlk olarak Lisrel programı kullanılarak migrenli hastalarda öz yeterlik, kendi kendine hastalık yönetimi ve yaşam kalitesi ilişsilerini gösteren bir yapısal eşitlik modeli oluşturulmuştur. Yapısal eşitlik modeli oluşturulunca, öncelikle modifikasyon indisleri incelenmiştir. Yapısal eşitlik modeli testi için modifikasyon indisleri kullanılarak doymuş model elde edilmiştir. Oluşturulan modelin uyum iyiliği istatistikleri incelenmiştir. Uyum iyiliği istatistikleri modelin kabul edilip edilemeyeceğine ilişkin bir takım kabul edilebilir sınır değerler vermektedir. İlk kullanılan uyum istatistiği Ki-kare $\left(\mathrm{x}^{2}\right)^{\prime}$ 'dir. Bir modelin kabul edilebilir olması için ki-kare değerinin anlamlı çıkmaması beklenir. Uygulamalarda ise ki-kare değerinin çoğu zaman anlamlı çıktığ1 görülür. Ki- kare değeri örneklem büyüklüğüne çok duyarlı olduğu için, çok küçük örneklemlerde ki kare değerinin çok kolay bir şekilde anlamsız çıktığ1, çok büyük örneklem gruplarında ise çoğu zaman anlamlı çıktığı görülmektedir. Ki-kare değerinin serbestlik derecesine bölünmesiyle elde edilen değer ki kare değerine göre daha güvenilirdir. Bu oranın 2 veya altında olması, modelin iyi bir model olduğunu, 5 veya daha altında bir değer olması ise, modelin kabul edilebilir bir uyum iyiliğine sahip olduğunu gösterir (Dursun \& Kocagöz 2010). Oluşturduğumuz modeli, uyum kriterlerine göre incelediğimizde; Ki kare değeri 2811.11; $\mathrm{p}=0.000$ istatistiksel olarak anlamlı bulunmuştur. $\chi^{2} / \mathrm{sd}=2811.11 / 955=2.94$ değeri $<3$ olması sebebiyle oluşturduğumuz modelin kabul edilebilir sınırlar içinde yer aldığı görülmüştür.

Kullanılan diğer uyum iyiliği istatistiği değerlerinden RMSEA, RMR ve SRMR'de değerlerin 0.05 'in altında olması iyi bir uyum iyiliği değerini, 0.08 'in altında olması ise kabul edilebilir bir uyum iyiliği değerini gösterir (Şimşek, 2007; İlhan \& Bayram, 2014). Bu uyum iyiliği istatistiklerinden hangisinin kullanılacağına dair de literatürde tam bir fikir birliği bulunmamaktadır. MacCallum ve Austin (2000) yapmış oldukları geniş bir meta analiz sonucunda, SRMR ve RMSEA'nin kullanılmasını önermektedirler. Bu araştırmada modelin RMSEA değerinin 0.075, SRMR değerinin de 0.072 kabul edilebilir uyum sınırları içinde olduğu görülmüştür (Tablo 1). Bu sonuç öz yeterlik kendi kendine hastalık yönetimi ve yaşam kalitesi modelinin oluşturulabileceğini göstermiştir.

Modelin uyum iyiliği değerleri kabul edilebilen değerler arasında yer alması sonucunda, yol analiziyle yapısal model test edilmiştir. Yapısal eşitlik modeline göre; migrenli hastalarda öz yeterliliğin, Kendi Kendine Hastalık Yönetimi Stratejileri Ölçeği alt boyutlarına doğrudan etkisi istatiksel olarak anlamlı bulunmuştur $(\mathrm{t}>1.96, \mathrm{p}<0.05)$. Migrenli hastalarda öz yeterlik arttıkça kendi kendine hastalık yönetim stratejileri kullanımı da artmıştır. French ve arkadaşlarının (2000) yaptığ1 araştırmada baş ağrısında öz yeterlik ile uğraş stratejileri arasındaki ilişkiyi değerlendirmişlerdir. Hastalığı önlemede ve yönetmede pozitif psikolojik uğraş stratejileri kullananlarda öz yeterlilik puanları, pozitif psikolojik uğraş stratejilerini kullanmayanlara göre daha yüksek belirlenmiştir. Aynı zamanda baş ağrısı yönetimde öz yeterlik ölçeği ile baş ağrısını önlemede ve yönetmede kullanılan pozitif psikolojik uğraş stratejileri arasındaki korelasyona bakılmış, pozitif yönde anlamlı ilişki bulunmuştur. Kendine güvenli olan bireyler, baş ağrısını yönetmede ve önlemede daha çok aktif uğraş stratejilerinde bulunmuşlardır. Diğer araştırmalarda da migrenli hastalarda öz yeterlik arttıkça davranışsal migren yönetimi artmıştır (French, et al., 2000; Seng \& Holroyd, 2010; Zacharoff \& Chiauzzi, 2012; Kleiboer, et al., 2014; Bromberg, et al., 2014). Kronik Böbrek Yetmezliği, Koroner Arter hastalığı, Tip 2 Diyabetli hastalarda yapılan araştırmalarda da öz yeterlik arttıkça hastalık yönetim davranışlarının arttığ1 görülmüştür (Haugland, Wahl, Hofoss \& DeVon, 2016; Wilski \& Tasiemski, 2016; Yeung \& Lu, 2014; Hunt, et al.,2012).

Araştırmamızda uygulanan yapısal eşitlik modellemesinde migrenli hastalarda öz yeterlik düzeyinin, yaşam kalitesi ölçeği alt boyutları üzerinde doğrudan etkisi ve dolaylı yoldan etkisi 
Özkan, İ., \& Olgun, N. (2017). Migrenli hastalarda özyeterlik, ağrılla başa çıkmada kendi genel yönetin stratejileri ve yaşam kalitesi arasındaki ilişkinin incelenmesi: Teorik bir modelin test edilmesi. Journal of Human Sciences, 14(4), 3389-3404. doi:10.14687/jhs.v14i4.4787

istatiksel olarak anlamlı bulunmuştur $(\mathrm{t}>1.96, \mathrm{p}<0.05)$. French ve arkadaşlarının (2000) baş ağrılı hastalarda yaptığı araştırmada öz yeterlilik ile baş ağrısına bağlı özürlülük arasındaki korelasyona bakıldığında, negatif yönde anlamlı bir ilişki bulunmuştur. Öz yeterlik artıkça baş ağrısının neden olduğu özürlülük azalmıştır. Nash ve Bach (2000) yaptığı araştırmada baş ağrisına spesifik öz yeterliğin yükselmesi ile baş ağrısı sıklığından bağımsız olarak hastalığın verdiği özürlülüğün düşüşü ile ilişkili bulunmuştur. Yapılan hiyerarşik çoklu regresyon analizinde öz yeterlilik, hastalı̆̆ın verdiği sakatlı̆̆1 belirlemede önemli bir belirleyici olarak bulunmuştur. Hansen ve arkadaşlarının (2009) Danimarka toplumunda baş ağrısı olan bireylerde yaptığı araştırmada, baş ağrısına spesifik öz yeterlilik ile iyi fiziksel fonksiyon ile düşük genel psikolojik sıkıntıyla arasındaki korelasyona bakıldığında pozitif bir ilişki bulunmuştur. Baş ağrısına spesifik öz yeterliliği puanları yüksek olan hastaların fiziksel ve sosyal fonksiyonları daha iyi bulunmuş, genel psikolojik sıkıntı semptomları azalmıştır. Çin'de kanser hastalarında öz yeterlik ve yaşam kalitesi arasındaki ilişkiyi yapısal eşitlik modelinde yol analizi yöntemiyle incelemişlerdir. Kanser hastalarında öz yeterliğin yaşam kalitesini doğrudan etkilediğini görmüşlerdir (Yeung \& Lu, 2014). Diğer kronik hastalıklarda yapılan araştırmalarda da öz yeterlik arttıkça hastaların yaşam kalitesi yükselmiştir (Haugland, Wahl, Hofoss \& DeVon 2016; Wilski \& Tasiemski, 2016; Yeung \& Lu, 2014; Hunt, et al.,2012). Literatür bilgisi oluşturduğumuz modelin hipotezlerini destekler niteliktedir.

Bu araştırmanın sonuçları değerlendirilirken bazı kısıtlılıkları göz önünde bulundurulmalıdır. Araştırma verilerin öz-raporlama ile toplanması öznelliğe ve değişkenler arasındaki ilişkilerin gerçeği tam olarak yansıtmamasına neden olmuş olabilir. Bu çalışmanın metodolojik olarak en önemli sınırlılığ1 çıkan ortak yöntem yanlılı̆̆ıdır. Bu sınırlılı̆̆ın temel nedeni çalışma verilerinin tek bir kaynaktan (migrenli hastalardan) toplanmasıdır. Bu durum gözlenen korelasyonların yapay bir şekilde artmasına neden olmuş olabilir.

\section{Sonuç}

Araştırma migrenli hastalarda öz yeterliğin kendi kendine hastalık yönetim stratejileri ve yaşam kalitesi arasında ilişki bir model oluşturularak, güçlü bir analiz yöntemi olan yapısal eşitlik modellemesi ile test edildi. Oluşturduğumuz modelde ileri sürdüğümüz hipotezler doğrulandı. Öz yeterliğin, migrenli hastaların yaşam kalitesini doğrudan ve kendi kendine hastalık yönetim stratejileri üzerinden dolaylı olarak etkilediği görüldü. Bu sonuca dayanarak; öz yeterlik, hastanın yaşam kalitesini, kendi kendine hastalık yönetim stratejilerini kullanma becerisinin bir belirleyicisi olarak düşünülebilir. Migrenli Hastaların yaşam kalitesini artırmak için migrenli hastaların hastalık yönetimi konusundaki öz yeterlikleri değerlendirilmeli, hemşirelik uygulamaları hastaların migren atağını önleme ve yönetme becerileri konusundaki kendilerine olan güvenini artıracak şekilde planlanmalidir.

\section{KAYNAKLAR}

Bandura, A.(1977). Self-efficacy: Toward a unifying theory of behavior change, Psychological Review 84: 191-215.

Bandura, A.(2004). The primacy of self-regulation in health promotion, Int Rev Appl Psychol, 54(2):245-254.

Brna, P., Gordon, K. \& Dooley, J. (2006). Health-related quality of life among Canadians with migraine. J Headache Pain 8:43-48. DOI: 10.1007/s10194-007-0320-4

Bromberg, J.,H., Wood, M.E., Black, R.A., Surette, D.A., Zacharoff, K.L. \&Chiauzzi, E.J. (2012). Randomized Trial of a Web-Based Intervention to Improve Migraine SelfManagement and Coping, Headache; 52, 2012, 244-261.

Dursun Y. \& Kocagöz E. (2010).Yapısal eşitlik modellemesi ve regresyon: karşılaştırmalı bir analiz. Erciyes Üniversitesi İktisadi ve İdari Bilimler Fakültesi Dergisi. 35:1-17 
Özkan, İ., \& Olgun, N. (2017). Migrenli hastalarda özyeterlik, ağrılla başa çıkmada kendi genel yönetin stratejileri ve yaşam kalitesi arasındaki ilişkinin incelenmesi: Teorik bir modelin test edilmesi. Journal of Human Sciences, 14(4), 3389-3404. doi:10.14687/ihs.v14i4.4787

Duru, G., Auray, J.P. \& Gaudin A.F. (2004) Impact of headache on quality of life in a general population survey in France (GRIM 2000 Study). Headache 44:571-580. DOI: 10.1111/j.1526-4610.2004.446005.x

Ertas, M., Baykan, B., Orhan, E.K., Zarifoglu M., Karli, N., Saip S., Onal, A.E. \& Siva, A. (2012). One-year prevalence and the impact of migraine and tension-type headache in Turkey: a nationwide home-based study in adults. J Headache Pain 13:147-157. DOI: 10.1007/s10194-011-0414-5. Epub 2012 Jan 14.

French, D.J., K.A. Holroyd, K.A., Pinell, C. \& et al.(2000).Perceived selfefficacy and headacherelated disability, Headache 40: 647-656. DOI: 10.1046/j.1526-4610.2000.040008647.x

Hansen JS, Bendtsen L, Jensen R. (2009). Psychometric properties of the Danish versions of Headache-Specific Locus of Control Scale and Headache Management Self-Efficacy Scale. J Headache Pain, 10:341-347.

Haugland, T., Wahl, A.K., Hofoss, D. \& DeVon H.A. (2016). Association between general selfefficacy,social support, cancer-related stress and physical health-related quality of life: a path model study in patients with neuroendocrine tumors. Health and Quality of Life Outcomes 14:11 DOI: 10.1186/s12955-016-0413-y

Headache Classification Committee of the International Headache Society (1988). Classifacation and diagnostic criteria forheadcahe disorders, cranial neuralgias and facial pain. Cephalalgia 8(7), Norwegian Press.

Headache Classification Committee of the International Headache Society (2013). The International Classification of headache disorders, 3rd edition (beta version). Cephalalgia 33(9):629-808. DOI:10.1177/0333102413485658

Hunt, C.W, Wilder, B., Steele, M.M. \& et al. (2012). Relationships amongself-efficacy, social support, social problem solving, and self-management in a rural sample living with type 2 diabetes mellitus. Res Theory Nurs Pract, 26: 126-141.

İlhan M. \& Bayram, Ç. (2014) Lısrel ve Amos programları kullanılarak gerçekleştirilen yapısal eşitlik modeli (yem) analizlerine ilişkin sonuçların karşılaştırılması. Journal of Measurement and Evaluation in Education and Psychology 5(2):26-42.

Kleiboer, A.K., Sorbi, M.J., Van, S.H.G., \& et al. (2014). Shortterm effectiveness of an online behavioral training in migraine self-management: A randomized controlled trial.Behav Res Ther 61: 61-69 DOI: 10.1016/j.brat.2014.07.009. Epub 2014 Jul 27.

Landy, S.H., Runken, M.C., Bell, C.F., Higbie, R.L. \& Haskins, L.S. (2011). Assessing the impact of migraine onset on work productivity. JOEM 53(1) :74-81 DOI: 10.1097/JOM.0b013e31812006365

MacCallum, R.C. \& Austin, J.T. (2000). Applications of structural equation modeling in psychological research. Annu Rev Psychol 51:201-26 DOI: 10.1146/annurev.psych.51.1.201

Marks, R., Allegrante, J., \& Lorig, K.(2005). A review and synthesis of research evidence for selfefficacy-enhancing interventions for reducing chronic disability: Implications for health education practice. Health Promote Pract. 6: 37-43. DOI: 10.1177/1524839904266790

Mennini, F.S., Gitto, L. \& Martelletti P. (2008).Improving care through health economicsanalyses: cost of illness and headache. J Headache Pain 9:199-206 DOI:10.1007/s10194-008-0051-9. Epub 2008 Jul 5

Nash JM, Bach AK. (2000). Self- efficacy account for levels of headache disability? Headache, 40:422.

Seng, E.K. \& Holroyd, K.A.(2010). Dynamics of change in selfefficacy and locus of control expectancies in the behavioral and drug treatment of severe migraine. Ann Behav Med 40: 235- 247 DOI: 10.1007/s12160-010-9223-3. 
Özkan, İ., \& Olgun, N. (2017). Migrenli hastalarda özyeterlik, ağrılla başa çıkmada kendi genel yönetin stratejileri ve yaşam kalitesi arasındaki ilişkinin incelenmesi: Teorik bir modelin test edilmesi. Journal of Human Sciences, 14(4), 3389-3404. doi:10.14687/ihs.v14i4.4787

Smitherman, T.A., Burch, R., Sheikh, H. \& Loder, E. (2013). The prevalence, impact, and treatment of migraine and severe headaches in the United States: a review of statistics from national surveillance studies. Headache 53(3):427-436. doi:10.1111/head. 12074.Epub2013Mar7

Steiner, T.J., Stovner, L.J. \& Gretchen, L.B. (2013) Migraine: the seventh disabler. J Headache Pain 14(1):1. DOI: $10.1186 / 1129-2377-14$

Stovner, L.J. \& Andree, C. (2010). Prevalence of headache in Europe: a review for the Eurolight project. J Headache Pain 11:289-299. DOI:10.1007/s10194-010-0217-0

Şimşek, Ö.F. (2007). Yapısal eşitlik modellemesine giriş, temel ilkeler ve lisrel uygulamaları. Ekinoks Yayınlar1, Ankara, $212 \mathrm{s.}$

Vladetic, M., Janculjak, D., Soldo, S.B., Krali, K. \& Buljan, K. (2017). Health-related quality of life and ways of coping with stress in patients with migraine. Neurol Sci 38:295-301 DOI: 10.1007/s10072-016-2759-7

Voerman, J.S. Klerk, C. \& et al.(2014). Long-term follow-up of home-based behavioral management training provided by migraine patients. Cephalalgia 34: 357-364 DOI: 10.1177/0333102413515337. Epub 2013 Dec 10.

Willis, E. (2016). Patients' self-efficacy within online health communities: facilitating chronic disease self-management behaviors through peer education, Health Communcation, 31(3): 299-307 DOI: 10.1080/10410236.2014.950019. Epub 2015 Sep 1.

Wilski, M., \& Tasiemski, T. (2016). Health-related quality of life in multiple sclerosis: role of cognitive appraisals of self, illness and treatment. Qual Life Res 25:1761-1770 DOI $10.1007 / \mathrm{s} 11136-015-1204-3$

Yeung, N.C.Y. \& Lu, Q. (2014) Affect as a mediator between self-efficacy and quality of life among Chinese cancer survivors in China. European Journal of Cancer Care 23:149-155 DOI: $10.1111 /$ ecc.12123

\section{Extended English Abstract}

\section{Introduction}

Self-efficacy specific for headache demonstrates the confidence in conducting the activities to prevent headache episodes or to manage headache-related inadequacy. In migraine management, adaptation of the patient to the disease is very important. Self-efficacy plays a key role in adaptation to the disease. The perceived individual differences concerning the interventions to be implemented in management and prevention of headaches are related to the individual adaptation to headache problems. In the studies conducted on individuals with migraine and other chronic disease, it was found that as self-efficacy increases, the quality of life and disease management behaviors increase but pain intensity, anxiety and depressive symptoms decrease. This study was designed to test a causality-based model showing the relationship between the self-efficacy, self-disease management and quality of life in migraine patients in the context of literature-based relationships and taking the social cognitive theory as basis.

\section{Method}

\subsection{Design, Sample and Place of the Study}

The study was designed as methodological and descriptive. The population of the study consisted of outpatients diagnosed with migraine according to the criteria of the International Headache Society (IHS) in the Neurology Outpatient clinic of a university hospital between June 2011 and June 2012. The sample size was calculated by considering the results of the previous study indicating that the migraine prevalence in Turkey was $16.4 \%$. The sample size was calculated as 258 when the prevalence was calculated as $16.4 \%$ with $\mathrm{d}=0.0052$ deviation and $95 \%$ possibility. In 
Özkan, İ., \& Olgun, N. (2017). Migrenli hastalarda özyeterlik, ağrılla başa çıkmada kendi genel yönetin stratejileri ve yaşam kalitesi arasındaki ilişkinin incelenmesi: Teorik bir modelin test edilmesi. Journal of Human Sciences, 14(4), 3389-3404. doi:10.14687/ihs.v14i4.4787

addition, when it was included by taking into consideration that 5-10 time sizes of the scale item number need to be considered in the methodological studies, the study consisted of 343 migraine patients who were selected by improbable sampling method.

\subsection{Collection of Study Data and Data Collection Tools}

The data were collected with self-report method by using interview form, Self-Disease Management Strategies Scale in Migraine patients developed by the researcher, The Quality of Life Scale in migraine patients, Self-Efficacy for Managing Chronic Disease 6-Item Scale (SEMCD) developed by Stanford Patient Education Research Center.

Self-Efficacy for Managing Chronic Disease 6-Item Scale (SEMCD): It was developed by Stanford Patient Education Research Center. The scale consists of one subscale and 6 items covering common symptom control, role function, emotional function, communication with physician which are common in many chronic diseases. The Cronbach's Alpha reliability coefficient of the original scale is 0.91 . Turkish adaptation of the scale was conducted by the researcher. Explanatory factor analysis was applied to reveal the structure validity of the scale. As a result of the factor analysis, the total explained variance of the variables was collected under a factor of $83.17 \%$. The internal consistency coefficient "Cronbach's Alpha" was calculated to calculate the reliability of the scale. The Cronbach's alpha reliability coefficient of the scale was found to be very high $(=0.958)$.

Self-Disease Management Strategies Scale in Migraine Patients: It is a scale consisting of 4 subscales and 17 items developed by the researcher in order to evaluate the strategies used by the patient in the prevention and management of the migraine related headache. Explanatory factor analysis was applied in order to reveal the construct validity of the scale. The variables were collected under four factors with total explained variance of $63.283 \%$ as a result of the factor analysis. The items in the first factor are called as palliative strategies, the items in the second factor are called as the strategies to be avoided, the items in the third factor are called as systematic cognitive and behavioral strategies and the items in the fourth factor are called as the muscle tension reduction strategies. The Cronbach's alpha reliability coefficient of SSDMSMP was found as 0.95 for the overall scale.

The Quality of Life Scale in Migraine Patients (QLSMP): It is a 5-point Likert type scale consisting of a total of 23 items and four subscales, developed by the researcher to evaluate the strategies used by the patient in managing and preventing the migraine-related headaches. An exploratory factor analysis was applied in this study to reveal the construct validity of the scale. The variables were collected under four factors with total explanatory variance of $72.374 \%$ as a result of the factor analysis. The items in the first factor are called as the lost in social functions, the items in the second factor are called as emotional field, the items in the third factor are called as restriction in the social relations, the items in the fourth factor are called as symptomatic field. The Cronbach's alpha reliability coefficient was found as 0.95 for the overall QLSMP.

\subsection{Statistical Analysis of the Data}

When the results obtained in the study were evaluated, SPSS (Statistical Package for Social Sciences) for windows 17.0 program was used for statistical analysis, lisrel 8.51 program was used for explanatory factor analysis, confirmatory factor analysis and structural equation model. The Kaiser-Meyer-Olkin (KMO) test and the Bartlett's Sphericity test were applied before factor analysis to determine if the sample size was sufficient for factor analysis. In order to evaluate the construct validity of scales, explanatory factor analysis and varimax' axis rotation basic component analysis were applied. Cronbach's alpha values were calculated by performing the internal consistency analysis for all of the items in the scale and each subscale of the scale. 
Özkan, İ., \& Olgun, N. (2017). Migrenli hastalarda özyeterlik, ağrılla başa çıkmada kendi genel yönetin stratejileri ve yaşam kalitesi arasındaki ilişkinin incelenmesi: Teorik bir modelin test edilmesi. Journal of Human Sciences, 14(4), 3389-3404. doi:10.14687/jhs.v14i4.4787

\section{Results}

3. 1. Creating the Theoretical Model: A structural equation model showing self-efficacy, selfdisease management and quality of life relationships in migraine patients was created. This theoretical model consisted of five parts: three measurement components and two structural equations. The measurement components are formed by: (i) Self-efficacy, the external variable of the study (ii) 4 observed variables of the self-disease management strategies which is the mediator variable of the study [Palliative strategies, strategies to be avoided, systematic cognitive and behavioral strategies, muscle tension reduction strategies]; (iii) 4 observed variables of the quality of life which is the internal variable of the study [loss in social functions, emotional field, restriction in social relations, and symptomatic field]. Structural equality components theoretically formulize the relationships between the latent variables: it was assumed that (i) Self-efficacy has direct effects on the quality of life and (ii) self-efficacy has effects on the quality of life through self-disease management skills.

3. 2. Testing the Theoretical Model: When the structural equation model was constructed using the Lisrel program, firstly the modification indices were examined. The errors of the items yon22 yon11, yon20 - yon2, yon13 - yon14, yon05 - yon23, myko14 - myko18, myko14 - myko15, myko16 - myko19, myko29 - myko30, myko05 - myko08, ozyet5 - ozyet6 were correlated in the model structure. These question matches were seen to be questions that are theoretically close to each other. For the structural equation model test, a saturated model was obtained using the modification indices. When the fit statistics of the model were examined, RMSEA value was found to be 0.075 . Chi square value of $2811.11 ; \mathrm{p}=0.000$ was found to be statistically significant. This value provides information on whether the difference between the expected covariance matrix and the observed covariance matrix was significant or not. It is desirable that the corresponding $\mathrm{p}$ value is not significant. In most cases, however, it is normal for the $\mathrm{p}$ value to be significant since the sample is large in confirmatory factor analysis. In this context, the fit was seen to be achieved in the confirmatory factor analysis. It was seen that $\chi^{2} / \mathrm{sd}=2811.11 / 955=2.94$ value was within the acceptable limits since it was $<3$. As a result of the fact that the fit indices of the model are in the acceptable values, testing of the structural model through path analysis was proceeded. In YEM application, the direct effect of the self-efficacy on the quality of life and its indirect effect on the self-disease management strategies were found to be statistically significant $(t>1.96, p<0.05)$.

\section{Conclusion, Recommendations:}

In the study, the correlation between the self-efficacy and self-disease management strategies and quality of life of migraine patients was tested with structural equation modeling, a powerful method of analysis by creating a model. The fit statistics of the model we created were found to be within acceptable boundaries. In YEM application, the direct effect of the self-efficacy on the quality of life and its indirect effect on the self-disease management strategies were found to be statistically significant. Based on this result; self-efficacy can be thought to be an indicator of the quality of life of the patient and the ability to use self- disease management strategies. In order to improve the quality of life of migraine patients, migraine patients' self-efficacy on disease management should be assessed and nursing practices should be planned to increase the patients' confidence in their skills to prevent and manage migraine attacks. 